\title{
LA ANTICORRUPCIÓN EN COLOMBIA, EL AGENTE ENCUBIERTO Y LA FUNCIÓN DE INTELIGENCIA*
}

\author{
José Ricardo Hernández Gómez ${ }^{* *}$
}

Fecha de recepción: 15 de enero de 2017

Fecha de evaluación: 6 de junio de 2017

Fecha de aprobación: 26 de octubre de 2017

Artículo de investigación

DOI: http://dx.doi.org/10.18359/prole.3332

Forma de citación: Hernández, J. R. (2018). La anticorrupción en Colombia, el agente encubierto y la función de inteligencia. Revista Prolegómenos Derechos y Valores, 21, 41, 99-114. DOI: http://dx.doi.org/10.18359/prole.3332

\section{RESUMEN}

El presente artículo tiene como propósito exponer a la comunidad científica la figura del agente encubierto como herramienta anticorrupción. El método descriptivo transversal, sustentado en el análisis de fuentes formales, estructuró la investigación desde una construcción gnoseológica del concepto de corrupción, señalando variados aportes de la jurisprudencia de la Corte Constitucional y enunciando la legislación vigente más relevante, para posteriormente evidenciar las deficiencias de la figura en términos jurídicos y operacionales, su falta de correspondencia con un modelo preventivo, así como la incapacidad de anticipar la comisión de los delitos relacionados con el fenómeno. A partir de las inconformidades, se exploró y propuso la utilización de la función de inteligencia y contrainteligencia como un prototipo anticipativo de excelencia, sustentado en su estructura teleológica y en su devenir histórico.

\section{Palabras clave:}

Corrupción, actividad encubierta, servicios de inteligencia.

* Este artículo pertenece al proyecto de investigación "Inteligencia y contrainteligencia, perspectivas desde la Corte Constitucional", desarrollado con el auspicio de la Corporación para la Investigación, el Desarrollo Científico y la Innovación.

** Abogado, posdoctor en Derechos Humanos, doctor en Antropología, máster en Inteligencia Estratégica y Prospectiva; especializado en Derecho Administrativo; Gerencia Financiera Sistematizada; Gerencia Tributaria; y Gerencia y Gestión Cultural Internacional. Exdirector de Investigación de la Escuela de Inteligencia y Contrainteligencia Brigadier General "Ricardo Charry Solano". Docente, investigador y experto en varias áreas de inteligencia y contrainteligencia. Actualmente es el presidente de la Corporación para la Investigación, el Desarrollo Científico y la Innovación y consultor e investigador en entidades públicas y privadas. Correo electrónico: presidencia@cidic.us 


\title{
ANTI-CORRUPTION IN COLOMBIA: THE UNDERCOVER AGENT AND THE INTELLIGENCE FUNCTION
}

\begin{abstract}
SUMMARY
The hereby article has as a goal to set forth the undercover agent as an anti-corruption tool to the scientific community. The transversal descriptive method - supported onto formal sources analysis - built the research from a gnoseological construction of the corruption concept, pointing out some inputs of the Constitutional Court and enunciating current and most relevant legislation in order to, subsequently, show the legal and operational deficiencies of that figure, its lack of concordance in relation to a preventive model and, its incapability to foresee crimes related to the phenomena. Based on those disagreements it was explored and proposed the use of both the intelligence and counterintelligence function as a preemptive prototype of excellence, supported on its teleological structure and its historical path.
\end{abstract}

\section{Keywords:}

Corruption, undercover activity, intelligence services.

\section{A ANTICORRUPÇÃO NA COLÔMBIA, O AGENTE DISFARÇADO E A FUNÇÃO DE INTELIGÊNCIA}

\section{RESUMO}

O presente artigo tem como objetivo expor à comunidade científica a figura do agente disfarçado como uma ferramenta anticorrupção. O método descritivo transversal, baseado na análise de fontes formais, estruturou a pesquisa a partir de uma construção gnoseológica do conceito de corrupção, apontando diversas contribuições da jurisprudência do Tribunal Constitucional e enunciando a legislação atual mais relevante, para posteriormente destacar as deficiências da figura em termos legais e operacionais, sua falta de correspondência com um modelo preventivo, bem como a incapacidade de antecipar a comissão dos crimes relacionados com o fenômeno. A partir dos desentendimentos, o uso da função de inteligência e contra inteligência foi explorado e proposto como um protótipo antecipatório de excelência, com base em sua estrutura teleológica e em sua evolução histórica.

\section{Palavras chave:}

Corrupção, atividade disfarçada, serviços de inteligência

\section{Introducción}

En el itinerario de lucha contra la corrupción en Colombia, surge la figura del agente encubierto "anticorrupción", objeto de estudio de la presente investigación y figura de la cual no existen estudios especializados en Colombia o un marco teórico de referencia, que permita contrastar los resultados obtenidos. Para comprender sus ca- racterísticas se tornó indispensable definir inicial y teleológicamente el concepto de corrupción, transitando por las sentencias relacionadas de la Corte Constitucional y la legislación anticorrupción, analizando sus elementos relevantes.

El debate conduce a establecer que la corrupción es la mayor amenaza contra la existencia del Estado, superando al terrorismo, al narcotráfico, 
al lavado de activos, al tráfico de armas y a otras amenazas de igual naturaleza, porque puede servirles de sustento y de elemento facilitador a sus realizaciones.

Dada la naturaleza y los grados de especialidad de la corrupción en especial pública, a la cual se refiere este documento y al estar directamente conectada con el ámbito de la res pública, colegimos que el fenómeno se inserta en el orden político, en el que se reproduce expansivamente desde la génesis y el ejercicio del poder, en el propio juego de elección y en el ejercicio democrático.

El Estado dispone de todos los recursos denominados "medios públicos", a través de los cuales procura la ejecución de sus objetivos; estos medios son de orden material e inmaterial, como los recursos económicos, jurídicos, humanos, informáticos o técnicos, en un contexto de amplio espectro y dentro del que se ubica el funcionario público como gestor. Estos medios son vitales en un esquema de lucha contra la corrupción, considerada como fenómeno, de su imbricación, mas no del hecho de que se desconozcan sus orígenes en fuentes netamente humanas y en comportamientos que tienen un fin común: la apropiación indebida de los bienes del Estado y/o la indebida utilización del poder.

Histórica y contradictoriamente ha existido una considerable dificultad para enfrentar las acciones de corrupción, debido a la gran cantidad de obstáculos legislativos, judiciales, políticos, de opinión, entre otros (Garzón, 2002) que se le oponen desde el seno del propio Estado, a los esfuerzos por reducirla; desde el cual surgen factores internos y externos de los diferentes órganos del poder, que facilitan y encubren este tipo de amenaza, con las graves repercusiones sociales.

Como se puede apreciar, la corrupción está asociada con diferentes factores, no requiere para su consolidación que solo esté conexa con aspectos de orden económico, en muchos de los casos se la vincula con prácticas culturales, de antigua data y que se estiman "social y políticamente normales" en la actividad del Estado, como por ejemplo derivar de la persona del funcionario las cualidades mismas del poder, para diferir trámites a discreción o impedir o dilatar el ejercicio y la satisfacción de derechos, entorpeciendo la normal realización de los fines del Estado, que nace de la inobservancia de las legítimas normas del servicio y del retardo en las prestaciones obligacionales del Estado. A partir de estos complejos sistemas se estructura la relevancia de su estudio.

Por las razones expuestas la hipótesis de trabajo se sustentó en la inviabilidad del agente encubierto como herramienta contra la corrupción, lo cual fue corroborado por los vacíos prácticos y jurídicos que se presentan desde su estudio teleológico y desde su deontológica operatividad.

Se propuso una solución a las falencias del instrumento en estudio y se procedió al análisis de las funciones de los organismos de inteligencia y contrainteligencia, orientadas fundamentalmente a la búsqueda de información que permita el adecuado conocimiento, comprensión, determinación e identificación de las diferentes formas de corrupción, sus estructuras operacionales, sus determinadores y operadores, sus metas y sus alcances, sus estructuras y sus cifras en todos sus escenarios, para que dicho conocimiento facilite la formulación de las decisiones que correspondan en cada situación particular y concreta y para que se diseñen los esquemas anticipativos, preventivos y correctivos que necesita el Estado para evitar que la corrupción se inserte de manera subrepticia en las instituciones estatales y se disemine en las estructuras medulares de la administración.

\section{A. Metodología}

A modo de introito, se tiene que la realización de toda investigación científica en las ciencias jurídicas, desarrolla un enfoque que determina como objeto de estudio, las fuentes formales y materiales del derecho; las primeras reúnen elementos como la Constitución, la ley, los decretos, los reglamentos y todo el orden kelseniano que se caracteriza por ser un producto tangible y las segundas conformadas por las realidades sociales, 
espectro donde la norma adquiere materialidad. Frente a este corto avance, el objeto de investigación jurídico-científica, son las normas, los hechos y los valores que coexisten en una unidad armónica, dialéctica y deontológica (Álvarez, 2009), dentro de la cual se puede clasificar esta investigación.

La actividad investigativa que transversalizó la labor, se puede definir como de estructura doctrinal-hermenéutica (Sánchez, 2011), sustentada en el método descriptivo transversal y respaldada en el análisis de fuentes formales. Su utilización satisfizo el estudio y la comprensión del problema de investigación que se planteó a modo de cuestionamiento: ¿es el agente encubierto anticorrupción una herramienta idónea para prevenir la corrupción?, lo cual cimentó el objetivo principal y del que derivaron como objetivos específicos el conocer las diferentes definiciones del término corrupción, las leyes adaptadas en Colombia y los conceptos que la Corte Constitucional había desarrollado sobre el tema, que se erigieron en las variables del análisis y condujeron al establecimiento de un objetivo alternativo subsidiario que solventara la necesidad de encontrar una solución a una respuesta negativa y que ordenara la función anticipativa de lucha contra la corrupción. En desarrollo de este marco metodológico se llegó al estudio de la función de inteligencia y contrainteligencia, para fortalecer la hipótesis de posibilidad de anticipación del proceso de corrupción.

\section{B. Resultados de la investigación}

\section{Construcción gnoseológica del fenómeno como objeto de conocimiento}

Los sentidos gnoseológicos de la acepción y de su tipología, deben considerarse e interpretarse a partir del conocimiento integral del fenómeno, en tanto amenaza, es decir, partiendo de una caracterización mínima de sus manifestaciones, para luego escalar en sus significados y poder unívocamente referirnos a ella en su contexto. Inicialmente abordaremos sus cauces etiológicos, más recientes, y que vertimos en la tabla 1.

Tabla 1. Comparativo de definiciones de corrupción por diferentes autores

\begin{tabular}{|c|c|}
\hline Autor & Definición \\
\hline Peter Eigen (2004, p. 20) & "[...] la mala utilización de un bien público en beneficio privado [...]". \\
\hline Susan Rose-Ackerman (2002, p. 360) & $\begin{array}{l}\text { "[...] un pago ilegal a un agente público para obtener un beneficio } \\
\text { que puede o no ser obtenido en ausencia del pago". }\end{array}$ \\
\hline Edward Christie Banfield (1975, p. 602) & $\begin{array}{l}\text { "[...] el comportamiento del agente que antepone sus intereses a los } \\
\text { de su función principal". }\end{array}$ \\
\hline William Michael Johnston (1982, p. 22) & $\begin{array}{l}\text { "[...] el abuso de una función pública para la obtención de un bene- } \\
\text { ficio privado". }\end{array}$ \\
\hline Daniel Treisman (2000, p. 11) & $\begin{array}{l}\text { "[...] el mal uso de la función pública para obtener ganancias perso- } \\
\text { nales [...]". }\end{array}$ \\
\hline Joseph LaPalombara (1994, p. 332) & $\begin{array}{l}\text { "[...] en beneficio personal o de personas cercanas a ellos, lo cual } \\
\text { manifiesta una conducta desviada de sus funciones institucionales". }\end{array}$ \\
\hline Transparencia Internacional (15 de mayo de 2001) & $\begin{array}{l}\text { "[...] se refiere a comportamientos por parte de funcionarios del sec- } \\
\text { tor público, ya sean políticos o servidores públicos, que los enriquece } \\
\text {-a ellos mismos o a sus allegados- inapropiada o ilegalmente me- } \\
\text { diante el mal uso del poder que se les ha encomendado [...]". }\end{array}$ \\
\hline $\begin{array}{l}\text { Arnold Austin Rogow y Harold Dwight Lasswell } \\
(1963, \text { p. 43) }\end{array}$ & $\begin{array}{l}\text { "Un sistema de orden público y cívico exalta el interés común ponién- } \\
\text { dolo por encima de los intereses particulares; transgredir el interés } \\
\text { común por los intereses particulares es corrupción". }\end{array}$ \\
\hline
\end{tabular}

Fuente: elaboración propia. 
A partir de la evaluación de las definiciones y de los estudios de los teóricos de la corrupción, en la investigación se construyó una definición que subsume la mayor parte de los criterios que se tienen en cuenta para caracterizarla, y a ella debe referirse de manera conclusiva y axiológica, como toda violación y/o acto desviado, de cualquier naturaleza, con fines económicos o no, ocasionada por la acción u omisión de los deberes institucionales, de quien debía procurar la realización de los fines de la administración pública y que en su lugar los impide, retarda o dificulta.

La corrupción como amenaza asume diversas, complejas y sofisticadas formas que la hacen difícil de controlar en un contexto donde el Estado mensura la satisfacción de necesidades y la prestación de servicios mediante índices de gestión (DNP, 2012), en los cuales el indicador se torna en lo importante, más que la calidad del servicio o el beneficio social. Algunos administradores del poder, lejos de ser o considerarse "operadores administrativos" o "servidores públicos" (ANC, art. 123, 1991), esto es, "funcionarios con vo- cación de servicio", han encontrado una forma singular de nombradía, a partir de la capacidad de "ejecución del presupuesto" con fines de lucro personal económicos y de relación (Garzón, 2002), llegando al extremo de que algunas entidades están "escrituradas" a "políticos" o a partidos políticos como pago de favores, como fuente del financiamiento de las campañas electorales o como favor de la misma estrategia de "gobernabilidad".

\section{Antecedentes jurisprudenciales}

Otra de las fuentes analizadas en el trabajo de investigación fue la doctrina derivada de las sentencias de la honorable Corte Constitucional, en especial la definición o el abordaje del tema, donde se permite vislumbrar la facies progresiva de las decisiones anticorrupción, que nos señalan su desarrollo jurídico, constituyéndose en referente de obligatoria consulta para conocer en profundidad las fuentes que históricamente han sustentado las más recientes normas anticorrupción, su orientación y praxis (véase tabla 2).

Tabla 2. Sentencias de la Corte Constitucional relacionadas con la amenaza de la corrupción

\begin{tabular}{l|l}
\hline \multicolumn{1}{c|}{ Sentencia } & \multicolumn{1}{c}{ Contenido de la sentencia } \\
\hline C-397/1998 & $\begin{array}{l}\text { "Las prácticas de corrupción desde luego son contrarias y nugatorias de los principios de igualdad, } \\
\text { moralidad, eficacia, economía, celeridad, imparcialidad y publicidad, ellas se oponen a la realización } \\
\text { efectiva de los mismos y los debilitan al punto de afectar gravemente el interés general. 'En todos los } \\
\text { casos y sin importar la forma en que se mire, la corrupción agrava la desigualdad. Al producir ese } \\
\text { efecto, siembra las semillas de tensiones sociales y políticas, amenaza la propia estructura de la socie- } \\
\text { dad y mina la eficacia del Estado y la legitimidad política de los gobiernos' [...]". }\end{array}$ \\
\hline C-030/1999 & $\begin{array}{l}\text { "La lucha contra la corrupción constituye una actividad íntimamente ligada a la realización de un fin } \\
\text { del Estado consistente en el ejercicio de la función pública, en todos los órdenes, según los cánones } \\
\text { más estrictos de moralidad y pulcritud. Este fin no es ajeno a ningún órgano del Estado. Por consi- } \\
\text { guiente, es esta una materia en la que se torna indispensable una actuación coordinada y armónica } \\
\text { por parte de todos los órganos del Estado. Si bien las distintas misiones asignadas a cada uno de los } \\
\text { órganos o ramas del poder público tienen distinta naturaleza -legislativa, judicial, administrativa y } \\
\text { disciplinaria-, la armonización como tal a la que alude el artículo 113 de la C.P., cuando compromete } \\
\text { variedad de órganos y de plexos competenciales, lo que se verifica en este caso, tiene una connota- } \\
\text { ción que no puede sin más confundirse con la que es específica de un órgano o de una función en } \\
\text { particular". }\end{array}$ \\
\hline
\end{tabular}




\begin{tabular}{|c|c|}
\hline Sentencia & Contenido de la sentencia \\
\hline C-088/2000 & $\begin{array}{l}\text { "Ha dado, pues, el Legislador, vigencia al principio de protección de los recursos presupuestales de } \\
\text { la Nación; ha cumplido con el deber de velar por la intangibilidad de los recursos públicos; ha pro- } \\
\text { pendido por la estricta observancia de la moralidad administrativa y ha dado pleno cumplimiento al } \\
\text { mandato contemplado en el artículo } 133 \text { de la Carta Política pues, ciertamente, la justicia y el bien } \\
\text { común requieren de herramientas que aseguren una mayor eficacia en la defensa del interés colec- } \\
\text { tivo representado en los recursos del patrimonio público. En la hora presente, sin lugar a dudas, los } \\
\text { más altos intereses nacionales, claman por su vigorosa protección, dada su grave afectación por la } \\
\text { corrupción que, como es sabido, también ha encontrado terreno fértil en la contratación pública". }\end{array}$ \\
\hline C-977/2002 & $\begin{array}{l}\text { "[...] De esta forma, considera que la mencionada ley 'no solo pretendía reconocer legalmente la } \\
\text { autonomía del derecho disciplinario, sino que buscaba fortalecer la función preventiva de los organis- } \\
\text { mos de control, dotando al Ministerio Público de herramientas eficaces para lograr la corrección de la } \\
\text { conducta de quienes desempeñan funciones públicas, y sobre todo luchar contra la corrupción admi- } \\
\text { nistrativa, que es uno de los mayores flagelos de nuestro país"” (Gaceta Congreso, } 27 \text { de junio 2000). }\end{array}$ \\
\hline C-851/2005 & $\begin{array}{l}\text { "[...] pues se configura inequívocamente una situación en la que se impone hacer prevalecer el inte- } \\
\text { rés general, artículo 1o. de la C.P., el cual se ve gravemente amenazado por prácticas de corrupción } \\
\text { que, como se dijo, atentan contra las bases mismas de la organización jurídico-política por la que optó } \\
\text { el Constituyente, y contra sus principios y valores fundamentales". }\end{array}$ \\
\hline C-028/2006 & $\begin{array}{l}\text { "Para tales efectos, esta Corporación analizará [...] (v) los diversos instrumentos internacionales exis- } \\
\text { tentes encaminados a luchar contra la corrupción en armonía con la Convención Americana sobre } \\
\text { Derechos Humanos; y (vi) la interpretación armónica y sistemática que debe realizarse entre la Cons- } \\
\text { titución y los tratados internacionales que hacen parte del bloque de constitucionalidad. } \\
{[\ldots . . .}\end{array}$ \\
\hline C-172/2006 & $\begin{array}{l}\text { "El análisis expuesto resulta plenamente aplicable para el asunto de la referencia. En efecto, la obli- } \\
\text { gación del Estado colombiano de implementar instrumentos jurídicos de diversa naturaleza, dirigidos } \\
\text { a la prevención de la corrupción es consecuencia natural de los postulados constitucionales que } \\
\text { propugnan por la transparencia en el ejercicio de la función pública como condición necesaria para } \\
\text { el debido funcionamiento del sistema democrático. } \\
\text { [...] } \\
\text { Así, ante la grave afectación que los actos de corrupción irrogan a bienes jurídicos intrínsecamente } \\
\text { valiosos en tanto están estrechamente relacionados con principios y valores constitucionales, toda ac- } \\
\text { tuación que tenga por objeto la prevención del fenómeno es, no solo acorde a la Carta, sino también } \\
\text { una vía adecuada y necesaria para la realización de las finalidades del aparato estatal". }\end{array}$ \\
\hline
\end{tabular}

Fuente: elaboración propia.

En estas irrupciones constitucionales se concluye que la Corte determina que la corrupción es taxonómica y principalmente una amenaza, genera tensiones sociales y públicas, agrava la desigualdad y se opone a la realización de los fines esenciales del Estado y su legitimidad política. Expresa que la lucha contra ella es un propósito que no debe ser ajeno a ningún órgano del Estado, quienes deben actuar armónica y coordinadamente en ese sentido, dado que la corrupción afecta los más altos valores $e$ intereses nacionales fundamentales. Manifiesta con especial énfasis que al combatir la corrupción no pueden irrespetarse los valores esenciales como el de proporcionalidad, razonabilidad, adecuación $e$ interdicción del exceso, entre otros y el Estado debe implementar los instrumentos jurídicos de diversa naturaleza dirigidos a la prevención de la corrupción, la cual es acorde con la Carta y la 
vía necesaria y adecuada para la realización de los objetivos del Estado.

\section{Legislación anticorrupción}

\section{El Estatuto Anticorrupción (ley 190/1995)}

En el año de 1995 se expide la ley 190, conocida como Estatuto Anticorrupción, cuyo objeto era la erradicación de la corrupción administrativa. Se establecieron variados mecanismos internos y externos, definiendo en su contenido un régimen de los servidores públicos, que fijaba un sistema de contratación y permanencia en el servicio, consagrando un régimen punitivo y un régimen financiero que buscaban controlar las actividades de flujo de capitales obtenidos mediante procesos de corrupción y en especial un sistema de control aplicable a las entidades sin ánimo de lucro.

En el mismo cuerpo legal se instituyeron los informes de gestión de las entidades públicas y se crearon la Comisión Nacional para la Moralización y la Comisión Nacional Ciudadana para la Lucha contra la Corrupción.

La norma fue sometida a auscultación constitucional y se modificó su contenido en varias ocasiones, por las leyes 200/1995, 443/1998, 600/2000, 617/2000 y 1221/2006. De igual forma fue reglamentada por los decretos 1477/1995, 1945/1995, 2150/1995, 2232/1995, 2329/1995, 1483/1996, 1964/1998, entre otros.

El resultado de la ley anticorrupción no logró el cumplimiento de sus objetivos, la deficiente visión y el restringido alcance especializaron la corrupción, con detrimento inexorable de los bienes del Estado e inclusive de su existencia (Procuraduría General de la Nación, 2012).

\section{La Ley Anticorrupción (ley 1474/2011)}

Estas variaciones y la necesidad de abordar la problemática con instrumentos eficientes y eficaces de lucha contra la corrupción dieron origen a la modificatoria de la ley 190/1995; por eso se tramitó ante el Congreso el Nuevo Estatuto Anticorrupción, cuyo contenido se circunscribe a los siguientes aspectos: acometer contra las estructuras organizadas de la corrupción, prohibiendo la contratación con el Estado de quienes hayan sido condenados por actos de corrupción; impedir a aquellos que financien campañas electorales se beneficien de contratos públicos y se impida a contratistas del Estado financiar campañas políticas; ampliar los términos de prescripción en materia penal y disciplinaria, como también los términos en las investigaciones por delitos contra la administración pública y por defraudaciones al patrimonio del Estado; evitar que aquellos que son o fueron servidores públicos gestionen intereses particulares o contraten con entidades donde se desempeñaron; orientar a los interventores de los contratos públicos para que garanticen una mayor vigilancia; generar herramientas para hacer de la lucha contra la corrupción una política de Estado mediante la Comisión Nacional para la Moralización, de la cual formarán parte representantes de las tres ramas del poder público y de los organismos de control.

De igual manera, la norma regula las operaciones encubiertas de carácter reactivo, contra la corrupción, agregando a la ley 906/2004 el artículo 242a, que quedará así:

Los mecanismos contemplados en los artículos 241 y 242 podrán utilizarse cuando se verifique la posible existencia de hechos de delitos contra la administración pública en una entidad pública. Cuando en investigaciones de corrupción, el agente encubierto, en desarrollo de la operación, cometa delitos contra la administración pública en coparticipación con la persona investigada, el agente encubierto quedará exonerado de responsabilidad, mientras que el indiciado o imputado responderá por el delito correspondiente.

\section{La ley 1778/2016 de anticorrupción transnacional}

La norma otorga facultades a la Superintendencia de Sociedades para investigar y sancionar 
a personas jurídicas matrices y subordinadas, que en el marco de conductas realizadas por sus empleados, contratistas, administradores y/o asociados den, ofrezcan y/o prometan a un servidor público extranjero, dinero o equivalente, beneficio o utilidad a cambio de que este último ejecute, omita y/o retarde actos ligados al ejercicio de sus funciones y en relación con un negocio o transacción internacional. Las sanciones serán administrativas.

Es una norma complementaria de la ley 1474/2011, responde a requerimientos y compromisos internacionales asumidos contra la corrupción transnacional y procura combatir dicha amenaza en este aspecto global.

La expedición de estas normas no ha cambiado la percepción de corrupción, no ha modificado las actividades relacionadas, ni su decrecimiento.

\section{El agente encubierto y sus operaciones}

\section{Definición de agente encubierto}

La Fiscalía en su Manual único de policía judicial lo define como:

[...] la infiltración ${ }^{1}$ y/o penetración ${ }^{2}$ a una organización delictiva realizada por servidores con funciones de Policía Judicial o particulares, cuando sea indispensable para el éxito de las tareas investigativas y con el fin de obtener información de interés para la investigación y EMP y EF (2005, p. 54).

De manera general y desde el Código de Procedimiento Penal, el agente encubierto es el funcionario de policía judicial y/o el particular, que mediante un plan metodológico

1 La infiltración se conoce en la doctrina militar como una técnica mediante la que se introducen unidades propias en el blanco u objetivo, para que recolecten información sobre actividades, capacidades, composición, planes, proyectos y otros elementos de interés.

2 La penetración también es una técnica, que consiste en lograr la colaboración consciente o no, de un miembro del blanco u objetivo, con el fin de obtener información confidencial, útil y fidedigna. elaborado por la Fiscalía General de la Nación, se infiltra en una organización criminal, para conocer su estructura, actividades, relaciones e integrantes.

Se ha determinado en consecuencia que el "agente encubierto anticorrupción" es aquel cuya actividad se asocia con la investigación de delitos y actividades que subyacen tras el fenómeno de la corrupción, cuando alcanza relevancia jurídica y que así sea determinado por el fiscal investigador.

\section{Características del agente encubierto}

Varias son las características del agente encubierto, entre las más importantes tenemos:

1. La reserva de identidad: esencia de la figura, obliga al agente a crear una historia de vida ficticia y una identidad diferente, con la cual realizará la actividad programada.

2. La designación: que solo pude hacer la Fiscalía General de la Nación, sujeta a criterios de necesidad, ponderación, legalidad y corrección en el comportamiento, para evitar excesos que contraríen la función pública y afecten la justicia y los tratados internacionales ratificados.

3. La aceptación: parece una condición lógica, pero que tiene relevancia jurídica en cuanto ningún funcionario de policía judicial o particular, puede ser obligado a adelantar actividades como agente encubierto.

4. La temporalidad: que limita las actividades y la designación a un año, prorrogable justificadamente por un periodo igual.

5. La limitación de sus actividades: que obliga al agente encubierto a ejecutar aquellas actividades legalmente determinadas en el plan metodológico que autoriza el fiscal, cuando hay un indiciado o imputado $y$ deben interesar a la investigación que se adelanta. 


\section{Actividades del agente encubierto}

Normativamente el agente encubierto ha sido definido por sus actividades como una herramienta útil de policía judicial con la que la Fiscalía General de la Nación, cuando tuviere motivos razonablemente fundados, de acuerdo con los medios cognitivos previstos en el Código de Procedimiento Penal, infiera que un indiciado o imputado continúa desarrollando una actividad criminal, mediante la cual designa y autoriza a funcionarios de la policía judicial o incluso a particulares, para que actúen en esta condición y realicen actos extrapenales de trascendencia jurídica como ejercer actos de comercio, asumir obligaciones, participar en reuniones de trabajo con el indiciado o imputado en su domicilio o lugar de trabajo y buscar y obtener información relevante, circunstancia que harán saber al fiscal para que se disponga que en el menor tiempo posible la policía judicial recoja los elementos materiales y evidencia física hallados (FGN, 2009).

Esta actividad se efectúa en la indagación o investigación, teniendo en cuenta la naturaleza y gravedad del delito y solicita al servidor de policía judicial respaldar los motivos fundados atendiendo lo dispuesto en el artículo $221 \mathrm{del}$ Código de Procedimiento Penal. El fiscal diseña un plan con el agente encubierto y la forma de recibir y entregar la información recopilada, controlando las actuaciones que este adelante, de tal forma que su actividad debe ceñirse al plan. Pudiendo utilizar además los medios que la técnica aconseje y que la norma permita.

Si el agente encubierto encuentra en los lugares donde ha actuado, información útil para la investigación, lo comunicará al fiscal, para que disponga una operación especial por parte de policía judicial, para la recolección de los elementos materiales de prueba y la evidencia física, sometiendo a revisión de legalidad formal y material el procedimiento adelantado, ante el juez de garantías y dentro de las 36 horas siguientes a la terminación de la operación encubierta.
Si se pretende que obren procesalmente la evidencia física y/o los elementos materiales de prueba recolectados, se debe establecer su autenticidad $y$ haber sido sometidos a cadena de custodia, trasladándola a la contraparte, al Ministerio Público y a la víctima para que expresen de manera sustentada si se excluye, rechaza, admite o inadmite y se evalúa su conducencia, pertinencia, eficacia y utilidad, con observancia del debido proceso, suscrito a la contradicción, publicidad, derecho de defensa y presunción de inocencia.

\section{El agente encubierto en la lucha contra la corrupción}

Frente a los delitos contra la administración pública asociados con la corrupción, la actividad del agente encubierto está condicionada según el Código de Procedimiento Penal a "cuando se verifique la posible existencia de hechos de delitos", es decir, no podrá recurrirse a dicha herramienta si antes no se constata la avenencia de un hecho punible.

Cuando se ha producido la consumación y la materialización de la conducta típica, de cualesquiera de los delitos asociados a la corrupción, el Estado podrá a través de la Fiscalía General de la Nación, recurrir al agente encubierto, con los requisitos ya expuestos. No es una actividad preventiva o anticipativa, sino de investigación para reconducirla al cauce judicial, sujeta a la apreciación subjetiva del fiscal, cuando

[...] tuviere motivos razonablemente fundados, de acuerdo con los medios cognoscitivos previstos en este código, para inferir que el indiciado o el imputado en la investigación que se adelanta, continúa desarrollando una actividad criminal [...] podrá ordenar la utilización de agentes encubiertos, siempre que resulte indispensable para el éxito de las tareas investigativas (CRP, 2004).

Por ello se predica que las operaciones encubiertas establecidas en el ámbito penal tienen un 
prominente carácter reactivo ${ }^{3}$ y forman parte de las herramientas utilizables por la policía judicial.

Esta sinopsis ayuda a inferir que el agente encubierto como herramienta en la lucha contra la corrupción desde su perspectiva normativa y deontológica no es adecuado para anticipar y/o prevenir el fenómeno de los delitos asociados con la corrupción, dado que su establecimiento y función deriva de la comisión previa de un delito y de la consecuente autorización de la Fiscalía General de la Nación, para la obtención de elementos materiales de prueba y evidencia física, bajo una estricta y obligatoria metodología de policía judicial.

Obsérvese que en ningún caso el agente puede tener iniciativa o incitar el delito, pues se estaría en presencia del agente provocador o determinador, lo cual pervierte los fines del Estado y anula la prosperidad de la actuación judicial (CSJ, proceso 19081, 22 de junio 2005). En este y otros eventos de igual connotación, se requiere una especial formación del agente encubierto que participa en operaciones contra los delitos que conforman las grandes variaciones y presentaciones de la corrupción, dado que su participación y la delicada enunciación normativa contienen un alto grado de especialización para su éxito. Así, la utilización del agente encubierto se supedita a necesidad de la Fiscalía en la investigación de los delitos consumados y para la obtención de elementos materiales de prueba o evidencia física. Esto patentiza la imposibilidad normativa de ser un instrumento que pueda prevenir la comisión de los delitos asociados con el fenómeno de la corrupción.

\section{El incremento de la corrupción}

En la actualidad se tiene el criterio invencible en la administración, de que la expedición de normativas anticorrupción per se-entre las cuales

3 Cuando se hace uso de las acciones u operaciones de carácter reactivo, se hace referencia a aquellas que se realizan como fruto de otras que las anteceden (causa) y que son el motivo de esa consecuente actividad (efecto). destacan el capítulo sobre Buen Gobierno en el Plan Nacional de Desarrollo; el Conpes 167 y la Política Pública Integral Anticorrupción (PPIA) de 2013; la Ley de Transparencia y Acceso a la Información Pública (ley 1712/2014) y a finales de 2011 la creación de la Secretaría de Transparencia para asesorar al presidente, ejercer la secretaría técnica de la Comisión Nacional para la Moralización y coordinar la implementación de la PPIA- es un mecanismo idóneo para la lucha contra la corrupción y/o cualquiera otra amenaza nacional o transnacional y que el establecimiento de "políticas" -procedimientos dentro de los cuales se encuentran los sancionatorios, el control interno y/o los sistemas de administración del riesgo, el área de innovación en la lucha contra la corrupción, entre otras-, es garantía suficiente para la erradicación de la amenaza de corrupción en el Estado.

Para contrastar los resultados de la investigación, se tiene como sustento el informe de Transparencia Internacional "Exportar corrupción. Informe de los países iberoamericanos" (2015), allí se resalta que 22 de los 41 países miembros de la Convención de la Organización para la Cooperación y el Desarrollo Económicos contra la corrupción transnacional no han emprendido ninguna investigación ni acción penal durante los últimos cuatro años. Dentro de ese grupo aparece Colombia con un cumplimiento nulo o escaso, después de 16 años de vigencia de la convención.

Asimismo, el Observatorio de Transparencia y Anticorrupción de la Secretaría de Transparencia de la Presidencia de la República en la gráfica 1 expone cómo las sanciones penales por corrupción en Colombia han tenido un incremento que evidencia el crecimiento de la amenaza.

A partir de la misma fuente, se tiene que en el 2015 se impusieron 496 sanciones penales, en el año 2014, 429, en el 2013, 340, en el 2012, 256 y en el año 2011, 325, los delitos más cometidos son el cohecho y el peculado, seguidos de la concusión y el prevaricato (véase gráfica 2). 


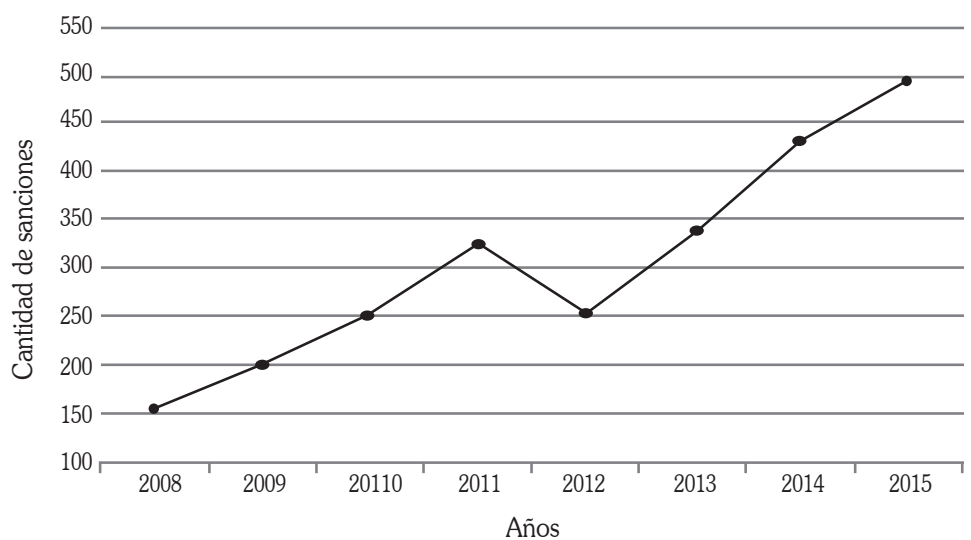

Gráfica 1. Sanciones penales por corrupción

Fuente: Sistema de Información de Registro de Sanciones y Causas de Inhabilidad y Procuraduría General de la Nación (2016).

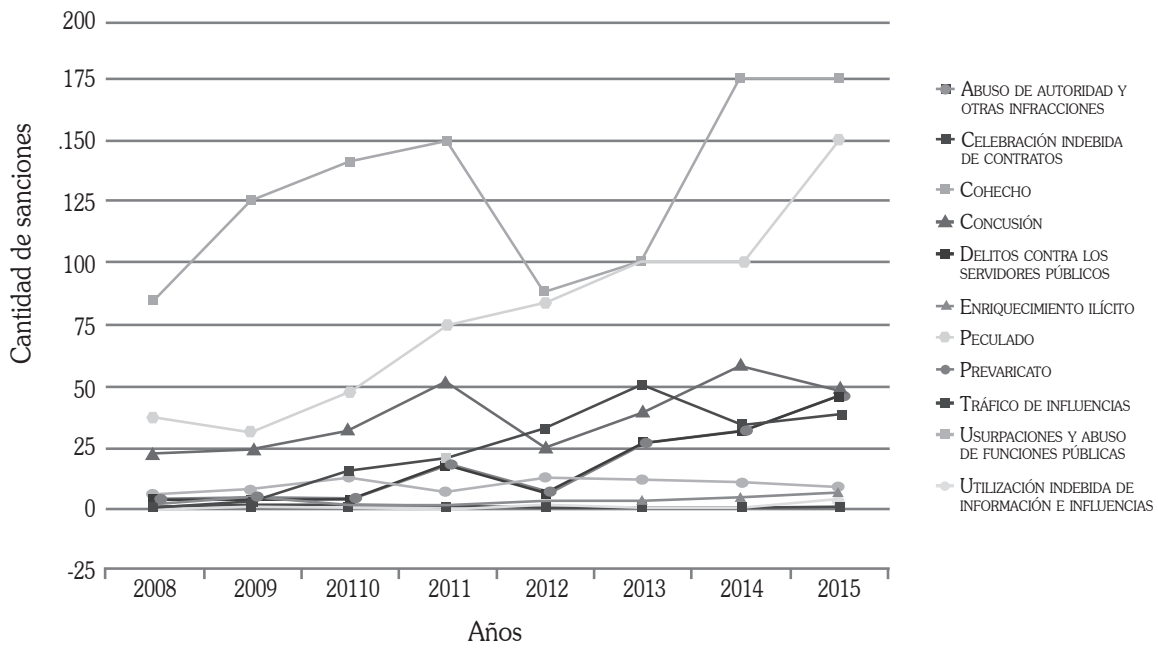

Gráfica 2. Delitos sancionados asociados con actos de corrupción

Fuente: Sistema de Información de Registro de Sanciones y Causas de Inhabilidad y Procuraduría General de la Nación (2016).

\section{Alternativa propositiva de implementación de un instrumento de prevención y lucha contra la corrupción}

Es menester que el Estado use los mecanismos $y$ funciones en su haber para hacer frente a la corrupción, y he aquí que el Estado tiene organismos especializados para prevenir y combatir esta amenaza, provenga del ámbito interno o externo; por ello deviene aplicable la ley 1621 del 17 de abril de 2013, que fortalece el marco normativo que le permite a los organismos de inteligencia y contrainteligencia, cumplir con su misión constitucional y legal, y que en su artículo 2 declara:

Definición de la función de inteligencia y contrainteligencia. La función de inteligencia 
y contrainteligencia es aquella que desarrollan los organismos especializados del Estado del orden nacional, utilizando medios humanos o técnicos para la recolección, procesamiento, análisis y difusión de información, con el objetivo de proteger los derechos humanos, prevenir y combatir amenazas internas 0 externas contra la vigencia del régimen democrático, el régimen constitucional y legal, la seguridad y la defensa nacional, y cumplir los demás fines enunciados en esta Ley.

Ahora, sus operaciones preferencialmente encubiertas, a través de sus agentes de inteligencia y contrainteligencia, no se encuentran en los rediles del derecho penal y no se soportan en la doctrina o metodología de policía judicial o lineamientos de la Fiscalía General de la Nación; y su rango de función determinada en la orden de operación o misión de trabajo, circunscrita a aspectos muy ligados y particulares de la amenaza, abarca elementos de suyo diferentes, pudiendo ser coincidentes, pero no útiles para el proceso penal, por disposición normativa consagrada en el artículo 36 de la ley antes nombrada.

En desarrollo de la función de inteligencia y de manera suficiente y proficiente se pueden adelantar acciones y operaciones para detectar e identificar las actividades de la corrupción como amenaza 4 , para que una vez identificadas, se tomen las decisiones necesarias para su "neutralización" y se dé curso si ello es viable, a las actividades de policía judicial, en los precisos términos contenidos en el artículo "242a" de la ley 906/2004, para facilitar la "judicialización" de personas dedicadas a delinquir mediante estructuras en extremo organizadas y dedicadas a la realización sofisticada de conductas punibles, atentatorias contra la administración pública. Es

$4 \quad$ El artículo 3 de la nueva Ley de Inteligencia y Contrainteligencia (ley 1621/2013) expresa que dichas actividades pueden ser llevadas a cabo por los organismos que faculte para ello la ley, por ende, la distancia jurídica es salvable y se complementa con el artículo 4 de protección de las personas e instituciones del Estado y sus recursos, en especial con la consecución de sus fines esenciales frente a amenazas que atenten contra ellas. muy importante analizar el artículo 36 de la Ley de Inteligencia y Contrainteligencia, referido a los informes, en tanto solo pueden constituir "criterio orientador" durante la indagación ${ }^{5}$, lo cual asegura la independencia funcional de estas actividades, frente al panel punitivo.

Las actividades de agente encubierto como policía judicial, solo pueden tener cabida una vez se verifique la posible existencia de hechos de delitos contra la administración pública, en tanto que la función de inteligencia y contrainteligencia cuenta con un espectro diferente, dado su carácter anticipativo y preventivo, que no desemboca de modo finalista en el proceso penal. Es muy frecuente confundir la función, los términos y las actividades de policía judicial, con la función, términos y actividades de inteligencia y contrainteligencia, generando distorsiones normativas e interpretativas que desnaturalizan sus respectivas esencialidades, cometiendo el error de endilgarle al funcionario de policía judicial labores de inteligencia y contrainteligencia y viceversa, eventos que son incompatibles por su naturaleza jurídica.

El marco de la función de inteligencia y contrainteligencia se limita a proteger los derechos humanos, prevenir y combatir amenazas internas o externas contra la vigencia del régimen democrático, el régimen constitucional y legal, la seguridad y la defensa nacional; adicionalmente tiene por finalidad: asegurar la consecución de los fines esenciales del Estado, la vigencia del régimen democrático, la integridad territorial, la soberanía, la seguridad y la defensa de la nación, la protección de las instituciones democráticas de la República, así como los derechos de las personas residentes en Colombia y de los ciudadanos colombianos en todo tiempo y lugar-sobre todo los derechos a la vida y la integridad personalfrente a amenazas tales como el terrorismo, el

\footnotetext{
5 La indagación se inicia con la noticia criminal y temporalmente puede transcurrir hasta la prescripción de la acción penal; es la fase de colección de elementos materiales probatorios y evidencia física, individualización de los autores o partícipes del hecho punible; su finalidad es determinar la ocurrencia o no de un hecho punible.
} 
crimen organizado, el narcotráfico, el secuestro, el tráfico de armas, municiones, explosivos y otros materiales relacionados, el lavado de activos, y otras amenazas similares e igualmente proteger los recursos naturales y los intereses económicos de la nación y el marco de la función de policía judicial se circunscribe a un único fin: el de obtener información útil a la investigación puesta en marcha por la Fiscalía General de la Nación.

La actual normativa anticorrupción -en especial el Código de Procedimiento Penal-adoptó de la doctrina de inteligencia sus figuras más cardinales y paradigmáticas como el análisis, el seguimiento pasivo, la entrega vigilada y la infiltración de organización criminal y la del agente encubierto, que de manera limitada fueron incorporadas en los artículo 241 y 242 citados (CRC, ley 906/2004), anexándolas a las actividades que pueden desplegar los organismos que desempeñan funciones de policía judicial, que como auxiliares de la administración de justicia, colaboran en una tarea eminentemente judicial y que conforman el presupuesto indispensable de las sentencias y providencias que profieren los jueces penales (CC, sentencia C-034/1993). Es decir, la función de policía judicial requiere la autorización de la Fiscalía General de la Nación, quien la dirige y coordina y que según la etapa procesal, actúa "sustancialmente" para comprobar hechos y circunstancias que importan al proceso, esto es: investigar los delitos cometidos.

Sin embargo, dada las limitaciones que se enunciaron en los programas metodológicos de policía judicial, conviene al Estado recurrir a las actividades de inteligencia y contrainteligencia, previo el diseño de un plan estratégico que afronte de modo integral la lucha contra la corrupción, de conformidad con las necesidades y las capacidades institucionales. Combatir la corrupción urge de herramientas que superen la función de policía judicial; la actividad discreta, clandestina y secreta de los actos de corrupción, que solo se evidencian una vez se produce el resultado, hace que en este ámbito los aspectos de anticipación y de prevención propios de la inteligencia y la contrainteligencia, cobren capital importancia.
Las actividades encubiertas de inteligencia y contrainteligencia pueden complementarse con algunas actividades de policía judicial, principalmente en demostrar el desarrollo de la conducta delictiva, la estructura criminal, sus integrantes y los demás hechos relevantes de la teoría del delito, que garanticen el éxito de la fase de judicialización, imperativo no permitido al agente de inteligencia y contrainteligencia, por no tener la investidura de policía judicial y de tenerla estaría en contradicción con su naturaleza normativa y la relación especial de sujeción (CC, sentencia T-350/2010).

Determinadas las diferencias fundamentales, debe considerarse que los actos de corrupción deben primordialmente anticiparse, prevenirse y/o neutralizarse.

La inteligencia en consecuencia, puede identificar plena y primariamente esta amenaza y evitar que logre vulnerar la estructura y función del Estado; por tanto, puede llegar a conducir las actividades para impedir que el resultado se produzca, esto es: que los fenómenos de corrupción se realicen.

La inteligencia mediante su doctrina, y a través de sus agentes especializados -quienes además se mantienen en un programa de formación permanente y científica, que incluye planeación estratégica, medios de búsqueda de información, procesamiento de la misma y análisis integral de esta amenaza-, puede caracterizarla, identificar a sus actores y sus estructuras, descubrir sus alcances, sus modus operandi, sus planes y proyecciones, las áreas de la administración donde va a ejecutar sus actos, sus relaciones con otras organizaciones y otros aspectos relevantes, cuyo resultado es un informe que le permite al decisor adoptar variadas alternativas, en escenarios de incertidumbre, para garantizar el logro esperado: erradicar la corrupción.

Estas precisiones revelan la importancia de concatenar todos los organismos de control, con las labores de inteligencia y contrainteligencia y las coordinaciones interinstitucionales, con el fin de identificar y "conocer" las actividades relacionadas con la corrupción desde sus primeras 
posibilidades, aspecto que aventaja las gestiones hasta ahora realizadas por el Estado y que implica la estructuración de iniciativas anticipativas, para modificar los resultados y evitar sus adversas manifestaciones.

\section{Conclusiones}

La corrupción en el ámbito administrativo es toda violación o acto desviado, de cualquier naturaleza, con fines económicos o no, ocasionada por la acción u omisión de los deberes institucionales, de quien debía procurar la realización de los fines de la administración pública, y que en su lugar los impide, retarda o dificulta.

La corrupción comprende una amenaza real y un problema estructural, que afecta la existencia del Estado y la ejecución de sus fines esenciales, asumiendo diversas, complejas y sofisticadas formas, difíciles de controlar en un escenario donde se mensura la satisfacción de necesidades y la prestación de los servicios a través de índices y abstracciones numéricas, no conectados con la calidad real de los servicios y su eficiente beneficio social.

Enconsecuencia, la Corte Constitucional señala como obligación constitucional del Estado colombiano la implementación de instrumentos jurídicos de diversa naturaleza, dirigidos a la prevención de la corrupción, que garanticen la transparencia de la función pública, como elemento necesario para el debido funcionamiento del sistema democrático. Concluyendo que todo acto preventivo del fenómeno de la corrupción además de constitucional es la vía correcta y necesaria para el logro de los fines del aparato estatal.

Los instrumentos jurídicos diseñados por el Estado no han sido suficientes para frenar la dinámica de la corrupción; la legislación anticorrupción y las herramientas que de ella se han derivado, no han logrado prevenirla y de acuerdo con las observaciones, el fenómeno ha crecido en múltiples aspectos, formas y sofisticación, convirtiendo los delitos asociados en empresas altamente complejas y transnacionales.
Dentro de las herramientas preventivas diseñadas para luchar contra la corrupción se encuentra la figura del agente encubierto, cuya naturaleza jurídica, funciones, tareas y objetivos, impiden la realización de actividades capaces de anticipar el fenómeno, dado que su labor comienza con la consumación del fenómeno e inicio de las indagaciones por parte de la Fiscalía General de la Nación, cuando se consuma el punible. La figura adicionalmente reviste mayor riesgo cuando se emplean particulares en la labor, cuya formación, capacidad e idoneidad, no son las adecuadas para la ejecución de esta clase de operaciones encubiertas.

A partir de la vigencia de la ley 1621/2013, se fortaleció el marco normativo de la función de inteligencia, estableciéndole como objetivo "prevenir y combatir, amenazas internas y externas" que atenten contra el sistema democrático. En ese sentido jurídico, existen estos organismos especializados del Estado, cuya idoneidad en la realización de actividades encubiertas, se sustenta en la formación y labor permanente de sus agentes, lo cual garantizaría el conocimiento del fenómeno, de los actores y de los escenarios asociados con la corrupción y el éxito de las operaciones anticorrupción, en los aspectos anticipativos y preventivos. La justificación jurídica de sus funciones en este aspecto anticorrupción, se soporta en las sentencias de la Corte Constitucional en cuanto "El Estado se ve gravemente amenazado por prácticas de corrupción" que "atentan contra el sistema democrático".

\section{Referencias}

Álvarez, G. (2009). Curso de investigación jurídica ( $3^{\mathrm{a}}$ ed.). Santiago de Chile: Legal Publishing.

Banfield, E. C. (1975). Corruption as a feature of governmental organization. Journal of Law and Economics, 18(3), 587-605.

Departamento Administrativo de la Función Pública. (2012). Guía metodológica para la construcción de indicadores de gestión. Bogotá: DAFP. 
Departamento Nacional de Planeación. (2009). Guía metodológica para la formulación de indicadores. Bogotá: DNP.

Eigen, P. (2004). Las redes de la corrupción. Madrid: Bronce.

Fiscalía General de la Nación. (2005). Manual único de policía judicial. Bogotá: Imprenta Nacional.

Fiscalía General de la Nación. (2009). Manual de procedimiento de Fiscalía en el sistema penal acusatorio. Bogotá: Imprenta Nacional.

Garzón, E. (2002). Acerca del concepto de corrupción. En: M. Carbonell \& R. Vásquez (coords.). Poder, derecho y corrupción (pp. 28-44). Ciudad de México: Siglo Veintiuno Editores.

Johnston, W. M. (1982). Political corruption and public policy in America. Monterrey: Brooks Cole.

LaPalombara, J. (1994). Structural and institutional aspects of corruption. Social Research, 61(2), 325-351.Procuraduría General de la Nación. (2010). Informe sobre presupuesto de inversión del Gobierno Central y entes territoriales. Bogotá: PGN.

Rogow, A. A. \& Lasswell, H. D. (1963). Power, corruption and rectitude. Nueva Jersey: Prentice Hall.

Rose-Ackerman, S. (2002). When is Corruption Harmful? En: A. J. Heidenheimer \& M. Johnston (eds.). Political corruption (3a ed.) (pp. 353-371). Londres: Transaction Publishers.

Sánchez, M. (2011). La metodología en la investigación jurídica: características peculiares y pautas generales para investigar en el derecho. Revista Telemática de Filosofía del Derecho, 14, 317-358.

Transparency International. (2015). Corruption perception index. Disponible en: http://transparencia.org.es/wp-content/ uploads/2016/01/america_ipc-015.pdf
Transparency International. (2015). Exportar corrupción. Informe de los países iberoamericanos. Disponible en: http://www. transparency.org/files/content/publication/2015_ExportarCorrupcion_InformesPaisesIberoamericanos_ES.pdf

Treisman, D. (2000). The causes of corruption: a cross-national study. Journal of Public Economics, 76(3), 399-457.

\section{Leyes:}

Asamblea Nacional Constituyente. (1991). Constitución Política. Colombia.

Congreso de la República de Colombia. (1995). Ley 190 "Por la cual se dictan normas tendientes a preservar la moralidad en la administración pública y se fijan disposiciones con el fin de erradicar la corrupción administrativa". Colombia.

Congreso de la República de Colombia. (2004). Ley 906-Código de Procedimiento Penal. Colombia.

Congreso de la República de Colombia. (2011). Ley 1474 "Por la cual se dictan normas orientadas a fortalecer los mecanismos de prevención, investigación y sanción de actos de corrupción y la efectividad del control de la gestión pública". Colombia.

Congreso de la República de Colombia. (2013). Ley 1621 "Por medio de la cual se expiden normas para fortalecer el marco jurídico que permite a los organismos que llevan a cabo actividades de inteligencia y contrainteligencia cumplir con su misión constitucional y legal, y se dictan otras disposiciones". Colombia.

Congreso de la República de Colombia. (2016). Ley 1778 "Por la cual se dictan normas sobre la responsabilidad de las personas jurídicas por actos de corrupción transnacional y se dictan otras disposiciones en materia de lucha contra la corrupción". Colombia. 


\section{Sentencias:}

Corte Constitucional de Colombia. (1993). Sentencia C-034. M. P.: Eduardo Cifuentes Muñoz. Colombia.

Corte Constitucional de Colombia. (1996). Sentencia C-709. M. P.: Antonio Barrera Carbonell. Colombia.

Corte Constitucional de Colombia. (1996). Sentencia C-319. M. P.: Vladimiro Naranjo Mesa. Colombia.
Corte Constitucional de Colombia. (1998). Sentencia C-397. M. P.: Fabio Morón Díaz. Colombia.

Corte Constitucional de Colombia. (2010). Sentencia T-350. M. P.: Humberto Antonio Sierra Porto. Colombia.

Corte Suprema de Justicia, Sala de Casación Penal. (22 de junio de 2005). Apelación, proceso 19081. M. P.: Germán Galán Castellanos. Colombia. 